\title{
Convergent Signaling Pathways Suggest Potential Therapeutic Targets
}

\section{in Autism \\ Yu-Chih Lin*}

Laboratory of Neuronal Connectivity, Program in Neuroscience, Hussman Institute for Autism, Baltimore, MD, USA

\section{Introduction}

Autism spectrum disorder (ASD) is a neurodevelopmental condition clinically diagnosed by differences in social interaction, communication, and behavior as described in the Diagnostic and Statistical Manual of Mental Disorders, Fifth Edition (DSM-5). The Centers for Disease Control and Prevention (CDC) estimates that about 1 in 68 children has been identified with autism in the United States. Autism can be diagnosed as early as the first three years of life, a critical period for establishing the brain circuitry [1]. Anatomical brain changes and differences in neuronal connectivity are often found in individuals with autism [2-4]. However, comorbidity with other neurological conditions can complicate the diagnosis and treatment of autism. Although the risk factors for autism are highly heterogeneous, genetic alteration is a prominent contribution to the condition. Genome-wide association studies (GWAS) of individuals with autism and their family members have revealed numerous genes that are associated with increased risk of autism (autism-risk genes). Specific mutations or deletions of these particular genes in animal models mimic a variety autistic-like behaviors providing a system to experimentally study autism [5]. Intriguingly, a small number of intracellular signaling pathways are repeatedly disrupted in response to the experimental alteration of different autism-risk genes. What insights can we get from studying these pathways and what therapeutic interventions can we achieve with the manipulations of these pathways? These are key questions to ask for translating the laboratory research into clinical application.

\section{mGluR5 pathway}

The group 1 metabotropic glutamate receptors (mGluR), including mGluR1 and mGluR5, are responsible for transducing signals from the neurotransmitter, glutamate, to activate protein synthesis in neurons. With its high expression in the cerebral cortex and hippocampus, the mGluR5 signaling pathway is essential for proper cortical development as well as the formation of learning and memory. mGluR5-dependent protein synthesis and synaptic plasticity are regulated by the expression of FMRP, the gene product of Fmrl, and the internalization of a-amino-3-hydroxy-5-Methyl4-isoxazolepropionate (AMPA) receptors in response to mGluR5 activation [6]. Increases in AMPA receptor internalization and mGluR5-dependent long-term depression (LTD) were found in mouse models of Fragile X syndrome, a neurodevelopmental condition with FMR1 alterations that shows comorbid symptoms with autism [6-8]. Interestingly, the scaffolding protein SHANK3, also an autism-risk gene, was found to couple with several postsynaptic density proteins, including mGluR5 [9]. Knockdown of SHANK3 shows impaired mGluR5-mediated synaptic plasticity suggesting that this pathway is potentially altered in autism with SHANK3 mutations [10]. Similarly, alterations with $U b e 3 a$, another autism-risk gene, also show defective mGluR5-dependet synaptic plasticity [11]. Application of mGluR5 antagonists, such as CTEP, MPEP, Fenobam, and Mavoglurant, has been shown to be promising in restoring some cellular phenotypes and experimentally in animal behaviors with Fmr1 alterations [12$14,8,15,16]$. Further investigation is necessary to determine whether these pharmacological agents can be clinically effective for individuals with autism carrying mutations other than FMR1.

\section{Publication History:}

Received: December 10, 2016

Accepted: December 15, 2016

Published: December 17, 2016

\section{Keywords:}

Autism, mGluR5, mTOR, GSK3 $\beta$

\section{mTOR pathway}

The mammalian target of rapamycin (mTOR) is a ubiquitously expressed serine/threonine kinase that acts as a node of convergence downstream of several neuronal surface receptors, including $\mathrm{N}$-methyl- ${ }_{\mathrm{D}}$-aspartate receptors (NMDARs), AMPARs, and mGluRs, to regulate translation initiation in response to changes of synaptic activity. mTOR is also a common downstream regulator of several signaling pathways, including phosphatidylinositol 3-kinase (PI3K), AKT, and tuberous sclerosis complex proteins 1 and 2 (TSC1/2). Following mTOR activation, p70 ribosomal S6 kinase 1 and 2 (S6K1/2) and the eIF4E-binding proteins (4E-BPs), two important units of the translation initiation machinery, are activated and repressed, respectively. In addition, mTOR phosphorylates protein kinase $\mathrm{C}$ (PKC) to regulate cytoskeletal assembly in neurons as part of the synaptic plasticity. Several experimental animals with genetic alterations of autism-risk genes Pten[17], Fmr1[18], Tsc1/2[19], or Mecp2[20] show defective synaptic plasticity and these animals have been identified with disruptions in the mTOR pathway. Interestingly, the mTOR pathway is upregulated in mice carrying defective gene products of Pten, Tsc1/2, or Fmr1, but downregulated in Mecp2-null mice. The mTOR inhibitor rapamycin (or Sirolimus) is originally used as an immunosuppressant to prevent organ rejection after a kidney transplant. Effective therapeutic results of rapamycin to ameliorate some of the autistic-like symptoms have been shown in animals bearing the autism-associated gene alterations [21-23]. The clinical trial of rapamycin application for autism is underway, however, determining how to minimize potential side effects caused by the extensive functions of mTOR pathway still requires further investigation.

\section{GSK3 $\beta$ pathway}

GSK3 $\beta$ is a serine/threonine kinase that is inactivated by phosphorylation. Several signaling molecules have been identified to regulate GSK3 $\beta$ activity. For example, receptor tyrosine kinases activate PI3K and AKT to phosphorylate GSK3 $\beta$ to turn off its activity to regulate cell survival. Alternatively, the small RhoGTPase Cdc42 is also activated by PI3K and subsequently activates Par complex to "Corresponding Author: Dr. Yu-Chih Lin, Laboratory of Neuronal Connectivity, Program in Neuroscience, Hussman Institute for Autism, Baltimore, MD, USA, Tel: (443)860-2580 (Ext. 733); E-mail: yclin@hussmanautism.org

Citation: Lin YC (2016) Convergent Signaling Pathways Suggest Potential Therapeutic Targets in Autism. Int J Clin Pharmacol Pharmacother 1: 119. doi: https://doi.org/10.15344/2016/2456-3501/119

Copyright: @ 2016 Lin. This is an open-access article distributed under the terms of the Creative Commons Attribution License, which permits unrestricted use, distribution, and reproduction in any medium, provided the original author and source are credited. 
phosphorylate GSK3 $\beta$ and regulates cytoskeletal machinery to control cell polarity and directed migration. In addition, the conical Wnt signaling regulates GSK3 $\beta$ inactivation via $\beta$-catenin and disheveled to function in axonal growth and migration. The hyperactivation of GSK3 $\beta$ pathway is often found in several mutant animals with certain autism-risk genes, including Cdk51[24], Pten[17], and Tsc1/2 [25]. Inhibition of GSK3 $\beta$ activity by insulin growth factor 1 (IGF1) administration or GSK3 $\beta$ inhibitors (e.g. lithium, SB216763) can rescue the dendritic phenotype and some autistic-like behaviors in these mutant mice [25-27]. In fact, lithium has been commonly used in the clinical practice as a mood stabilizer in several psychiatric conditions, including autism. In addition, IGF-1 is currently in clinical trials for several neuropsychiatric conditions, such as Rett's syndrome, which exhibits comorbidity with autism [28].

\section{Conclusion}

Because of the highly heterogeneous gene mutations found in individuals with autism, it is challenging to pinpoint which genes should be prioritized in the study of autism. As a result, several available medications target the symptoms rather than the physiological mechanisms that are altered in autism. A growing amount of experimental evidence has shown that signaling pathways involving mGluR5, mTOR, and GSK3 $\beta$ are often disrupted when a subset of the autism-risk genes are altered. Interestingly, all three pathways can be further linked together, as GSK3 $\beta$ and mTOR are both regulated by PI3K/AKT, which are activated by PTEN, a dualspecificity lipid/protein tyrosine phosphatase, in response to the activation of membrane-bound receptors, including mGluR5. The crosstalk among these signaling molecules further emphasizes the notion that autism may involve the disruption of selective pathways that are common to numerous specific risk genes. Further research should focus on exploring in detail the molecular mechanisms and the signaling pathways underlying autistic behaviors. Understanding the molecular mechanisms of the affected pathways will help us design targeted therapeutic interventions to provide effective treatment for autism.

\section{Competing Interests}

The authors declare that they have no competing interests.

\section{Acknowledgements}

The author thank Dr. John Hussman and members of Lin lab for critical evaluation of the manuscript.

\section{Funding}

This work is supported by Hussman Foundation grant HIAS15003 to Y.-C. L.

\section{References}

1. Huttenlocher PR, Dabholkar AS (1997) Regional differences in synaptogenesis in human cerebral cortex. J Comp Neurol 387: 167-178.

2. Amaral DG, Schumann CM, Nordahl CW (2008) Neuroanatomy of autism. Trends Neurosci 31: 137-145.

3. Donovan AP, Basson MA (2016) The neuroanatomy of autism - a developmental perspective. J Anat. [Epub ahead of print].

4. Palmen SJ, van Engeland H, Hof PR, Schmitz C (2004) Neuropathological findings in autism. Brain 127: 2572-2583.

5. Kazdoba TM, Leach PT, Yang M, Silverman JL, Solomon M, et al. (2016) Translational Mouse Models of Autism: Advancing Toward Pharmacological Therapeutics. Curr Top Behav Neurosci 28: 1-52.
6. Li J, Pelletier MR, Perez Velazquez JL, Carlen PL (2002) Reduced cortical synaptic plasticity and GluR1 expression associated with fragile $\mathrm{X}$ mental retardation protein deficiency. Mol Cell Neurosci 19: 138-151.

7. Huber KM, Gallagher SM, Warren ST, Bear MF (2002) Altered synaptic plasticity in a mouse model of fragile $X$ mental retardation. Proc Natl Acad Sci U S A 99: 7746-7750.

8. Nakamoto M, Nalavadi V, Epstein MP, Narayanan U, Bassell GJ, et al. (2007) Fragile $X$ mental retardation protein deficiency leads to excessive mGluR5-dependent internalization of AMPA receptors. Proc Natl Acad Sci U S A 104: 15537-15542.

9. Tu JC, Xiao B, Naisbitt S, Yuan JP, Petralia RS, et al. (1999) Coupling of mGluR/Homer and PSD-95 complexes by the Shank family of postsynaptic density proteins. Neuron 23: 583-592.

10. Verpelli C, Dvoretskova E, Vicidomini C, Rossi F, Chiappalone M, et al. (2011) Importance of Shank3 protein in regulating metabotropic glutamate receptor 5 (mGluR5) expression and signaling at synapses. J Biol Chem 286: 34839-34850.

11. Pignatelli M, Piccinin S, Molinaro G, Di Menna L, Riozzi B, et al. (2014) Changes in mGlu5 receptor-dependent synaptic plasticity and coupling to homer proteins in the hippocampus of Ube3A hemizygous mice modeling angelman syndrome. J Neurosci 34: 4558-4566.

12. Michalon A, Bruns A, Risterucci C, Honer M, Ballard TM, et al. (2014) Chronic metabotropic glutamate receptor 5 inhibition corrects local alterations of brain activity and improves cognitive performance in fragile $X$ mice. Biol Psychiatry 75: 189-197.

13. Michalon A, Sidorov M, Ballard TM, Ozmen L, Spooren W, et al. (2012) Chronic pharmacological mGlu5 inhibition corrects fragile $X$ in adult mice. Neuron 74: 49-56.

14. de Vrij FM, Levenga J, van der Linde HC, Koekkoek SK, De Zeeuw CI, et al. (2008) Rescue of behavioral phenotype and neuronal protrusion morphology in Fmr1 KO mice. Neurobiol Dis 31: 127-132.

15. Tucker B, Richards RI, Lardelli M (2006) Contribution of mGluR and Fmr1 functional pathways to neurite morphogenesis, craniofacial development and fragile X syndrome. Hum Mol Genet 15: 3446-3458.

16. Pop AS, Levenga J, de Esch CE, Buijsen RA, Nieuwenhuizen IM, et al. (2014) Rescue of dendritic spine phenotype in Fmr1 KO mice with the mGluR5 antagonist AFQ056/Mavoglurant. Psychopharmacology (Berl) 231: 1227-1235.

17. Kwon CH, Luikart BW, Powell CM, Zhou J, Matheny SA, et al. (2006) Pten regulates neuronal arborization and social interaction in mice. Neuron 50 : 377-388.

18. Sharma A, Hoeffer CA, Takayasu Y, Miyawaki T, McBride SM, et al. (2010) Dysregulation of mTOR signaling in fragile $X$ syndrome. J Neurosci 30 : 694-702.

19. Meikle L, Pollizzi K, Egnor A, Kramvis I, Lane H, et al. (2008) Response of a neuronal model of tuberous sclerosis to mammalian target of rapamycin (mTOR) inhibitors: effects on mTORC1 and Akt signaling lead to improved survival and function. J Neurosci 28: 5422-5432.

20. Ricciardi S, Boggio EM, Grosso S, Lonetti G, Forlani G, et al. (2011) Reduced AKT/mTOR signaling and protein synthesis dysregulation in a Rett syndrome animal model. Hum Mol Genet 20: 1182-1196.

21. Tsai PT, Hull C, Chu Y, Greene-Colozzi E, Sadowski AR, et al. (2012) Autistic-like behaviour and cerebellar dysfunction in Purkinje cell Tsc1 mutant mice. Nature 488: 647-651.

22. Zhou J, Blundell J, Ogawa S, Kwon CH, Zhang W, et al. (2009) Pharmacological inhibition of mTORC1 suppresses anatomical, cellular, and behavioral abnormalities in neural-specific Pten knock-out mice. $\mathrm{J}$ Neurosci 29: 1773-1783.

23. Ehninger D, Silva AJ (2011) Rapamycin for treating Tuberous sclerosis and Autism spectrum disorders. Trends Mol Med 17: 78-87.

24. Fuchs C, Trazzi S, Torricella R, Viggiano R, De Franceschi M, et al. (2014) Loss of CDKL5 impairs survival and dendritic growth of newborn neurons by altering AKT/GSK-3i ${ }^{2}$ signaling. Neurobiol Dis 70: $53-68$.

25. Mak BC, Kenerson HL, Aicher LD, Barnes EA, Yeung RS (2005) Aberrant beta-catenin signaling in tuberous sclerosis. Am J Pathol 167: 107-116.

26. Fuchs C, Rimondini R, Viggiano R, Trazzi S, De Franceschi M, et al. (2015) Inhibition of GSK3 $\hat{I}^{2}$ rescues hippocampal development and learning in a mouse model of CDKL5 disorder. Neurobiol Dis 82: 298-310. 
Citation: Lin YC (2016) Convergent Signaling Pathways Suggest Potential Therapeutic Targets in Autism. Int J Clin Pharmacol Pharmacother 1: 119. doi: https:// doi.org/10.15344/2016/2456-3501/119

Page 3 of 3

27. Della Sala G, Putignano E, Chelini G, Melani R, Calcagno E, et al. (2016) Dendritic Spine Instability in a Mouse Model of CDKL5 Disorder Is Rescued by Insulin-like Growth Factor 1. Biol Psychiatry 80: 302-311.

28. Khwaja OS, Ho E, Barnes KV, O'Leary HM, Pereira LM, et al. (2014) Safety, pharmacokinetics, and preliminary assessment of efficacy of mecasermin (recombinant human IGF-1) for the treatment of Rett syndrome. Proc Nat Acad Sci U S A 111: 4596-4601. 